\title{
Surface-active properties of organic matter in the North Adriatic Sea
}

\author{
B. Gašparović* and B. Ćosović \\ Center for Marine and Environmental Research, Ruđer Bošković Institute, POB 180, HR- \\ 10002 Zagreb, Croatia \\ *gaspar@rudjer.irb.hr
}

\section{Abstract}

Characterization of surface-active organic substances has been performed in the North Adriatic Sea, in surface and bottom layers, during the year 2000. Surfaceactive substances (SAS), their hydrophobicity and acidity, were estimated with alternating current voltammetry (in-phase mode) using o-nitrophenol as an electrochemical probe. Depending on hydrophobicity and acidity of present SAS electrochemical characteristics of the o-nitrophenol probe are changing in a specific way. Normalization of the change of prepeak height as an indication of organic matter acidity to shift of peak potential as a measure of hydrophobicity give indication of relative acidity of present SAS. Experiment with model substances showed that humic and fulvic acids contribute the highest to the relative acidity, while biogenic surface-active organic substances as proteins, polysaccharides and lipids contribute lower to the relative acidity.

Surface water layer is characterized with higher phytoplankton excretion during whole year concluded from higher contribution of biogenic organic substances to surfactant activity. Humic and fulvic substances dominate in surfactant activity in the bottom layer. Proteinaceous material is found in a heterodispersed fraction during supposed phytoplankton blooms that were in March, July, September and even December, in the Northern Adriatic, connected to unexpectedly high temperatures. Surfactant activity of particulate fraction was found to be mainly less than $10 \%$. Exceptions were obtained in April and October when surfactant activity of particulate fraction contributed up to 55 and $20 \%$, respectively. 
Keywords: organic matter, surfactant activity, acidic properties, North Adriatic Sea, electrochemical probe, $o$-nitrophenol reduction.

\section{Introduction}

Dissolved organic matter in the sea is one of the largest reservoirs of organic carbon on the Earth making it an important pool of carbon in the global carbon cycling (Williams \& Druffel, 1987). Its distribution, concentration and composition in the marine environment are influenced by biological, chemical and physical processes such as phytoplankton production and excretion, release of organic matter by auto-lysis (Baines \& Pace, 1991), egestion by grazers (Lampert, 1978), microbial production and excretion (Azam \& Cho, 1987), chemical removal processes such as flocculation, precipitation, sedimentation and adsorption on phase boundaries, photochemical degradation (Moran \& Zepp), physical processes such as mixing.

To improve knowledge about complex mixture of organic matter in seawater a lot of work has been done as use of different separation techniques that are based on different physico-chemical characteristics of present organic matter. Ultrafiltration techniques separate organic matter to the fractions of different molecular weight/size (Guo et al., 1995), different resins are used for the separation according to different hydrophobic/hydrophilic properties (Vojvodić et al., 1994) or according to acido-basic properties (Afcharian et al., 1997). The characterization of the extracts is delicate and calls for complex and very specific analyses giving insight into the molecular level, such as determination of lipids and fatty acids (Derieux et al., 1998), amino acids (Hubberten et al., 1994), sugars (Benner \& Opsahl, 2001). Determination of dissolved and particulate organic carbon (DOC and POC) is now unavoidable for the organic matter study in seawater. However, DOC is a general parameter and does not provide information on the nature of organic matter in seawater.

Surface-active substances (SAS) are organic substances of specific structure, possessing structural groups that are repulsed from water (hydrophobic groups) and 
structural groups that have strong affinity to the water (hydrophilic groups). Due to amphiphatic molecular structure SAS may form micelles. Surfactant activity (SA) of some hydrophilic substances originates from their high molecular weight as in a case of polysaccharides (Plavšić \& Ćosović, 2000). SAS adsorb at natural phase boundaries (Liss, 1975; Stumm, 1992) where they influence mass and energy transport. This is especially important for the air/sea boundary concerning problem of global warming. SAS participate in hydrophobic as well as electrostatic interactions, so they react with each others, minerals and biological membranes. As SAS make up a large fraction of organic matter (Hunter \& Liss, 1982) and are very reactive part of organic matter, their characterization might contribute to the knowledge of organic matter cycling in the seas.

\section{Study area}

The North Adriatic Sea is a shallow, semi-enclosed basin, and is one of the most productive region of the Mediterranean. It receives significant freshwater inputs mainly by the Po River, whose waters contribute at least $50 \%$ to nutrients input to the North Adriatic (Degobbis \& Gilmartin, 1990). The Po River influence is relevant in all the main biogeochemical cycles, determining nutrient availability and changing the light absorption characteristics of waters. This river is the most important contributor of organic matter to the North Adriatic Sea. The loads of total organic carbon and nitrogen were estimated as $25.5 \times 10^{4}$ and $15.5 \times 10^{4}$ tones per year, respectively (Pettine et al., 1998). The average DOC in Po River is $2.1 \mathrm{mg} / \mathrm{l}$. DOC values of Po River do not show any clear seasonal behavior or significant difference between surface and bottom layers (Pettine et al., 1998).

During summer, the North Adriatic Sea is characterized with semi-closed circulation pattern that prevents exchange of water masses with the middle Adriatic, and with high vertical stability of the strongly stratified water column (Franco et al., 1982). This situation leads to the accumulation of organic matter and to hypoxic or anoxic crises in bottom layers and appearance of mucilage aggregates (Degobbis et al., 1995) that are happening more frequently in last fifteen years. This accumulation is attributed to the allochthonous and autochthonous increase due to increased of the Po River freshwater 
residence time and due to inefficient organic matter uptake by bacterioplankton (Pettine et al., 2001).

Long-term investigations (1989-1993) of DOC values in the North Adriatic Sea showed that DOC concentrations are in the range of 1.13 to $3.06 \mathrm{mg} / 1$ (Vojvodic \& Ćosović, 1996). The general characteristic of the distribution of the surface-active organic matter for the North Adriatic is a sinusoidal change of SA with lowest values obtained in the winter and highest during the summer. The highest SA values in the surface layer coincide with the spring and autumn pulses of nutrient load with the Po River (Gašparović \& Ćosović, 2001).

Annual peaks of phytoplankton biomass in the North Adriatic Sea are caused mainly due to increase in diatom abundance, while small size cells such as microflagelates dominate during periods of low chlorophyll $a$ concentration in summer (Mozetič et al., 1998). Increased diatom contribution to the phytoplankton community in the North Adriatic is observed since eighties. Diatoms are well known as producers of hydrophilic organic compounds, mostly carbohydrates (Myklestad, 1995). During decay phases of the phytoplankton bloom high molecular weight exudates can be produced in larger quantities and accumulated in the absence of a significant grazing and microheterotrophic activity (Degobbis et al., 1995).

As zone that receives significant terrestrial input and maintains high level of primary production the North Adriatic Sea can be considered very complex environment to examine the dynamic nature of SAS. In this paper temporal and spatial distributions and changes of surface-active substances over one year period are presented. Also, by using electrochemical probe the acidic properties of the dominant type of SAS of surface and bottom seawater were estimated.

\section{Experimental}




\section{Sampling field}

Seasonal and spatial distributions of SAS were determined, in the North Adriatic Sea, along transect from the Po River mouth to Rovinj town (Figure 1). Stations A 001, A 013, 101 and 108 are under the direct influence of the Po River discharge. Po River waters rarely influence stations 103 to RV 001, which are close to the Croatian coast. The stations along this transect were considered as representative for the North Adriatic (Gilmartin et al., 1990) and their basic hydrographic properties, nutrients and phytoplankton dynamics have been regularly surveyed since 1976 at intervals from monthly to seasonally.

In this study approx. monthly sampling was performed during the period from January to December, 2000. Samples were collected at the 8 stations across the sea between Italian and and Croatian coasts from the RV "Vila Velebita" (Figure 1) with 5liter Niskin bottles from the surface $(0.5 \mathrm{~m})$ and bottom layers $(27-37 \mathrm{~m})$. Samples were stored in dark glass bottles at $4{ }^{\circ} \mathrm{C}$ and measured within $24 \mathrm{~h}$ in the land laboratory.

\section{Material and methods}

Surface-actice substances were determined by phase-sensitive alternating current (a.c.) voltammetry by in-phase measurements using $o$-nitrophenol as an electrochemical probe, as described in previous papers (Gašparović \& Ćosović 1994, 1995). All measurements were performed using the EDT-ECP-100 Modular Research Polarograph, connected to the ECP-110 unit (EDT) and to a Hewlett-Packard 7045 A recorder. The frequency of a.c. voltage was $170 \mathrm{~Hz}$, and the p-p amplitude was $10 \mathrm{mV}$. Scan rate was $20 \mathrm{mV} / \mathrm{s}$. All the experiments were performed using a three-electrode system with the hanging mercury drop electrode (Metrohm, Switzerland) as the working electrode. $\mathrm{An} \mathrm{Ag} / \mathrm{AgCl} / 3 \mathrm{M} \mathrm{KCl}$ electrode was used as the reference electrode and a platinum wire as the auxiliary electrode. $O$-nitrophenol $\left(10^{-4} \mathrm{M}\right)$ was added to the model solution or marine samples immediately before the voltammetric measurement. Seawater samples were measured without any previous treatment, except addition of o-nitrophenol. Exception were samples with mucilage aggregates that were diluted with $0.5 \mathrm{M} \mathrm{NaCl}$. Model solutions were $0.55 \mathrm{M} \mathrm{NaCl}$ and $2 \times 10^{-3} \mathrm{M} \mathrm{NaHCO}_{3}$, at $\mathrm{pH} 8.3$, simulating seawater conditions. 
Organic matter was accumulated on the mercury electrode by stirring the solution at the potential of $-0.35 \mathrm{~V}$ for 1 and $3 \mathrm{~min}$, before the potential scanning.

The sampling, storage and transport to the laboratory and general handling with the samples were carried out according to the procedure that was observed and not changed through the years, thus preventing incident that may influence the composition or the characteristics of the samples. This is manifested in the repeatability of the trends and correlation between the measurements data through prolonged (several years) period of measurements.

The surfactant activity of the complex mixture of organic matter in natural seawater sample is expressed as the equivalent concentration of the nonionic surfactant Triton-X100 (T-X-100), which gives the same effect to o-nitrophenol peak potential shift $(\Delta \mathrm{E})$ as the natural organic substances in the sample. The calibration curve for the dependence of the $o$-nitrophenol peak potential shift on the T-X-100 concentration was presented in a previous paper (Gašparović \& Ćosović, 2001). Lower limit of detection expressed as T$\mathrm{X}-100$ concentration is $0.02 \mathrm{mg} / \mathrm{l}$.

Surfactant activity was evaluated for the dissolved and particulate SAS. SA of the dissolved SAS was measured in the filtered sample. SA of the particulate fraction was evaluated as a difference between SA detected for the non-filtered and filtered samples. Seawater samples were filtered (-50 kPa) just before measuring using precombusted (450 $\left.{ }^{\circ} \mathrm{C} / 5 \mathrm{~h}\right)$ Whatman $\mathrm{GF} / \mathrm{F}$ glass fibre filters $(0.7 \mu \mathrm{m}$ pore size $)$ to separate particulate and dissolved material. Filtering system was prepared prior to the sample filtering by rinsing with Milli-Q water. Blank of filtered Milli-Q water should correspond to unfiltered Milli-Q water.

In some nonfiltered seawater samples contribution of heterodispersed particles was detected, but their contribution to the surfactant activity was considered only qualitatively due to the irreproducible effects on the electrode surface. Their contribution was detected as an occasional hit of particle to electrode surface causing big decrease of capacitance and big changes of electrochemical characteristics of o-nitrophenol probe (compare curves 3 and 4 in Figure 2). 
Temperature of seawater was measured with a standard oceanographic reversing thermometer (accuracy $\pm 0.01{ }^{\circ} \mathrm{C}$ ) and salinity with a YEO-KAL 601Mk1V high precision bench salinometer (accuracy \pm 0.01 ).

The o-nitrophenol and albumin (egg) (Sigma Chemical Co., USA), dextran (average mol wt. 500000, Serva, Germany), and linoleic acid (Fluka, Switzerland) were used without further purification. Humic and fulvic acids provided from University of Perpignan, France where isolated from lagoon sediment. All solutions were prepared with deionised water obtained with Milly-Q Water System (Millipore, Switzerland). Carbonate buffer was used to maintain $\mathrm{pH}$ 8.4. All solutions were purged with pure nitrogen for $10 \mathrm{~min}$ prior to voltammetric measurements.

Characterization of surface-active substances by using o-nitrophenol as an electrochemical probe

All voltammetric measurements of o-nitrophenol included two scans: the first scan, recorded from the accumulation potential $(-0.35 \mathrm{~V})$ up to $-0.90 \mathrm{~V}$, represents the main onitrophenol peak, and the second scan, recorded immediately after the potential was returned to the initial potential at the same mercury drop electrode, represents the onitrophenol prepeak.

In the presence of adsorbed layers of organic matter on the mercury electrode, electrochemical characteristics of o-nitrophenol such as peak potential, height and shape, and prepeak height, are changing in significantly different ways, depending on different properties of adsorbed organic substances like hydrophobicity, acidity, molecular weight, etc. Based on this phenomenon, a method was developed for rough characterization of organic matter in seawater samples by measuring the shift of the o-nitrophenol peak potential (Gašparović \& Ćosović, 1994) and change of prepeak height (Gašparović \& Ćosović, 1995). The o-nitrophenol has a voltammetric reduction peak at $-0.555 \mathrm{~V}$ under the $\mathrm{pH}$ conditions of natural seawater. In the presence of organic matter adsorbed onto the mercury electrode, the o-nitrophenol peak potential is shifted toward more negative potentials, depending on the concentration and the hydrophobicity of adsorbed organic substances. 
The height of the prepeak is extremely sensitive to the acidity of organic matter adsorbed on the mercury electrode at the $\mathrm{pH}$ of natural seawater (Gašparović \& Ćosović, 1995). The o-nitrophenol prepeak increases in the presence of adsorbed layers of negatively charged organic substances such as humic acid, up to 6 times, few time for fulvic acid and proteins, while in the presence of adsorbed uncharged polysaccharides, represented by model substances of dextran type, there is no increase in the o-nitrophenol prepeak height. In experiment with model acidic dextrans of increasing acidity it was shown that increase of prepeak height is proportional to the acidity of investigated organic substance (Gašparović et al., 1998a). The examples of the o-nitrophenol peak potential shift and increase of prepeak height are given in Figure 2.

All the results of peak potential shift and prepeak height for seawater samples and model solutions of $\mathrm{T}-\mathrm{X}-100$ were normalized to $0 \mathrm{~min}$ accumulation time and possible differences due to different $\mathrm{pH}$ were avoided. The reproducibility of electrochemical measurements was $8-10 \%$.

\section{Results and discussion}

Seasonal and spatial variability of surfactant activity in North Adriatic Sea

Surfactant activity (SA) of bottom and surface layer of the North Adriatic seawater samples have been measured in 2000. Temporal distributions of surfactant activity, temperature and salinity for bottom and surface water for two representative stations, Station 107, far from the Po River, and Station A 001 which is under direct and constant influence of Po River discharge, are presented in the Figure $3 \mathrm{a}$ and b. Station 107 has been investigated since 1998, so distributions are presented for the time period since 1998, although results for 1998 and 1999 have been already published (Gašparović \& Ćosović, 2001). SA distribution correlated with temperature and salinity changes, in the surface layer, showing, in general, sinusoidal changes, as it was observed earlier (Gašparović \& Ćosović, 2001). Such trend s not observed for the surface layer of Stations 
A 001 and A 013. Spatial distributions of SA values, temperature and salinity of surface and bottom waters are presented in Figure 4 for February (Figure $4 \mathrm{a}$ and b), August (Figure $4 \mathrm{c}$ and $\mathrm{d}$ ), and December (Figure 4e and f), 2000. Surfactant activity values mostly decreased from the Po River mouth toward Croatian coast. This was much more pronounced for the surface layer.

SA values of the bottom layer of all stations, during year 2000 were in the range from 0.042 to $0.111 \mathrm{mg} / \mathrm{l}$ in equiv. T-X-100. Lowest values were obtained in January, while in August highest SA values were recorded. Bottom temperature had lowest values in February (between 8.0 and $9.3{ }^{\circ} \mathrm{C}$ ) and reached maximum in October, between 15.9 and $20.5^{\circ} \mathrm{C}$. Salinity of the bottom layer was relatively uniform, around 38 .

Surface temperature of the whole region had lowest values in February and highest in August. Salinity varies in surface layer. At stations more close to Po River salinity changes were very pronounced toward end of the year. Also salinity was very low at beginning of the year for stations A 001 and A 013.

According to surfactant activity distribution, the investigated transect in the Northern Adriatic Sea might be divided to two regions: eastern, including stations 103 to RV 001, and western, including stations from A 013 to 101. Surfactant activity of the surface layer of the eastern region had sinusoidal change with superposed oscillations (see Fig 4a), as it was obtained for the years 1998 and 1999 (Gašparović \& Ćosović, 2001). SA ranged from 0.048 , in February, to $0.140 \mathrm{mg} / 1$ in equiv. T-X-100, detected in June, in the period of mucilage appearance in that year. Surface SA of the western region ranged from 0.048 to $0.158 \mathrm{mg} / 1$ in equiv. T-X-100. Very high SA for stations A 013 to 101 were observed from August to December, leading to change of sinusoidal pattern. This was attributed to the high input of nutrients with riverine waters that is directly connected to increased SAS concentrations due to increase of phytoplankton production and excretion. Unexpectedly high SA values were measured in December in surface waters of this region, between 0.088 and $0.135 \mathrm{mg} / \mathrm{l}$ in equiv. T-X-100. This high SA was attributed to increase of phytoplankton production due to combined effects of high temperature and riverine water influence on biological activity.

The contribution of particulate fraction to the total SA is presented in the Figure 5 for Station 105. The similar trend is observed for the whole investigated region. During 
the whole year SA mostly originated from dissolved fraction while particulate fraction contributed less than $10 \%$ of total SA for the two investigated layers with exception in April (55\%) and in October (approx. $20 \%$ ). As early spring and autumn are periods of common diatom blooms in the North Adriatic (Revelante \& Gilmartin, 1976a,b; Gilmartin \& Revelante, 1983) the increased contribution of particulate SAS in April and October might be a consequence of sticking of freshly produced dissolved and/or colloidal organic matter excreted during the bloom. In accordance with this it was shown in particle size spectra in a simulated phytoplankton bloom that there was continuous increase in concentration and size of particles throughout the bloom (Li \& Logan, 1995). During nutrient enriched phytoplankton culture growth on the North Adriatic seawater, where diatoms were developed as dominant phytoplankton species, increased concentration of dissolved and particulate SAS were observed. SA was ascribed to the increased presence of, primarily, polysaccharides and also protein type substances (Gašparović et al., 1998b). Sticky organic material may form larger aggregates and finally mucilages, which more frequently appear in the North Adriatic in the last 10-15 years. Indeed, appearance of mucilages was noticed at late May and middle June in 2000 (see Table 3).

\section{Determination of the relative acidity of the $S A S$}

Marine organic matter is very complex mixture but can be divided in few general classes, humic and fulvic acids and proteins, lipids and carbohydrates which are mostly of biogenic origin. All of these substances have acid-base and surface-active properties and can be electrochemicaly analysed (Gašparović et al., 1998a). To better characterize complex mixture of organic substances in the seawater, relative increase of prepeak height $\left(\left(\mathrm{I}_{\mathrm{a}} / \mathrm{I}_{\mathrm{a} 0}-1\right)\right.$ as the indication of acidity of molecules $)$ is normalized to belonging surfactant activity (expressed as equiv. concentration of T-X-100) of the same chosen model substances (Figure 6a). This value is called relative acidity and represents an arbitrary unit of acidity per surfactant activity $(1 / \mathrm{mg})$. The same was done with chosen model substances as shown in Figure 6a that was used for comparison with seawater 
samples. Here, it can be seen that the highest contributions to the acidity or highest relative acidity, in broad surfactant activity range, have polyelectrolyte humic and fulvic type substances. Relative acidity further decreases in the case of biogenic substances in the following order: albumin (model for proteins), xanthan (model of acidic polysaccharide) and linoleic acid (model for lipid material). In a case of neutral polysaccharide dextran T-500 relative acidity is zero as expected for a case of non-acidic substance. So, it could be assumed that lowering of acidity ratio, bellow $201 / \mathrm{mg}$, is an indication of increased contribution of biogenic SAS to surfactant activity of seawater samples. Results in Figure 6a are shown for the surfactant activity range typical for the North Adriatic seawater samples, from $0.04-0.18 \mathrm{mg} / 1 \mathrm{~T}-\mathrm{X}-100.86 \%$ of North Adriatic seawater samples have surfactant activity $\leq 0.13 \mathrm{mg} / \mathrm{l} \mathrm{T}-\mathrm{X}-100$. Decreasing part of relative acidity curve, at SA higher than $0.13 \mathrm{mg} / 1 \mathrm{~T}-\mathrm{X}-100$, is a consequence of change of reduction mechanism of o-nitrophenol probe and not of change of acidity properties of model substances.

In the Figure $6 \mathrm{~b}$ surfactant activities of increasing concentration of selected model substances are given. The adsorption of SAS on the mercury electrode is dominated by their hydrophobic properties. An excellent correlation is observed between the adsorption constant and the hydrophobic properties (as defined by the octanol/water coefficient) (Ulrich et al., 1988). Very hydrophobic linoleic acid can be detected in one order of magnitude lower concentration range in comparison to the other model substances presented in Figure 6b. For example, very hydrophilic polysaccharide xanthan is electrochemically measurable at higher concentrations, more than $1 \mathrm{mg} / \mathrm{l}$. Humic and fulvic substances are slightly more hydrophobic than proteins and dextrans. Humic and fulvic substances contribute to dissolved organic matter between 40 and $60 \%$ (Thurman, 1985). Proteins made up 13-44 \% of water column organic matter (Romankevich, 1984). The concentration of carbohydrates in the North Adriatic Sea, were found mainly phytoplankton originated, and varied in a range of 0.2 to $1.9 \mathrm{mg} / 1$, representing $10-65 \%$ of the total DOC (Terzić et al., 1998). The content of dissolved lipids in the Northern Adriatic amounts 3.0-4.0 \% of DOC in seawater (Derieux et al., 1998). Fractionation of SAS on the XAD-8 resin according to hydrophobic properties showed that humic and fulvic substances are mostly distributed in the hydrophobic acid fraction as well as 
proteins, fatty acids belong to the hydrophobic neutral fraction, while polysaccharides are mostly found in the hydrophilic fraction (Vojvodić et al., 1994, Gašparović et al., 1997).

From the relative acidity value it was attempted to estimate which type of organic matter contributed to the surfactant activity, more acidic polyelectrolyte humic and fulvic surface-active organic matter or biogenic organic matter as proteins, polysaccharides and lipids. In the Table 1 averaged relative acidity values estimated for whole region, for bottom and surface seawater samples, in the year 2000 are given. Relative acidities of the bottom layer during the year were in the range from $17.3-23.21 / \mathrm{mg}$, while of the surface water were in the range from $10.8-16.01 / \mathrm{mg}$. Higher relative acidity values in the bottom layer indicate that humic and fulvic substances have higher contribution to the surfactant activity. Lower relative acidity values detected in the surface waters, in comparison to the bottom layer, indicate higher contribution of less acidic, biogenic SAS to surfactant activity of the sample, that imply higher phytoplankton excretion in this layer. The lower relative acidity values for surface layer were detected in the period from June to September. These freshly produced SAS, which are mostly hydrophilic, less acidic substances, are reactive to degradation and/or alteration in the marine environment of the North Adriatic Sea. So, half-life time of the fresh surface-active organic matter may be accounted less than few months. It is known that macromolecular dissolved organic matter cycles rapidly in coastal regions (Santschi et al., 1995). A fluorescence study of both marine and freshwater samples showed that organic matter freshly excreted by algae may be partially remineralized, but a fraction of the degraded products may be transformed into humic-like matter (Parlanti et al., 2000). A model study developed for the North Adriatic Sea, suggests that this region has significant microbial recycling (Vichi et al., 1998).

Chemical characterization of the dissolved organic matter in the Hiroshima bay showed that hydrophilic organic matter is two to three times more concentrated than hydrophobic organic matter. Hydrophilic organic matter is mainly autochthonous produced during summer and is subject to biodegradation (Fukushima et al., 2001). In the Delaware Estuary examination of the chemical composition of high molecular weight dissolved organic matter showed that primary source of polysaccharides and amino acids is algal production. More degraded organic matter was found in the turbid middle estuary 
while fresh dissolved organic matter was found in the lower estuary (Mannino \& Harvey, 2000).

Production of biogenic SAS is connected mainly to the phytoplankton excretion and it markedly differs in different layers, bottom and surface. This is due to the fact that nutrient ratios of the North Adriatic are significantly different in surface layer, due to freshwater nutrient input and phytoplankton assimilation, than in subeuphotic regeneration bottom layer (Degobbis, 1990). Nutrient sources support a highly productive coastal belt with high primary production. Photosynthetic efficiency increases with increase of nutrient concentration as well as primary production rate was found to be higher in the narrow coastal belt of western coastal waters of the Adriatic sea (Zoppini et al., 1995).

Relative acidity values did not exhibit significant difference between stations (Table 2) what was unexpected for stations A 001 and A 013 that are under constant influence of riverine waters. It has been expected that seawater of these two stations would have more acidic properties due to expected high quantity of riverine organic matter discharged into the Northern Adriatic Sea (Pettine et al., 1998). Dominant organic substances in the riverine waters are coloured hydrophobic humic type substances (Ćosović et al., 1985, Fukushima et al., 2001) which are very acidic (see Figure 6). As it is not the case it is supposed that riverine SAS are removed from the estuarine waters very fast. Another explanation is that freshly produced SAS had dominant effect on the mercury electrode and riverine acidic organic matter cannot be recognized by its relative acidity value. Fukushima et al. (2001) found that hydrophobic dissolved organic matter in the Hiroshima bay had similar concentration as in the riverine waters but is chemically different. Pettine et al. (1998) found that behavior of organic matter in the Po River mixing zone was conservative in low to medium solid transport conditions, but have strong negative deviation with respect to the dilution line during high solid transport, presumably due to both settling of particulate matter in the pro-delta region and bacterial utilization of organic matter. Benner \& Opsahl (2001) suggest that loss of terrigenous dissolved organic matter at low salinities is due to flocculation but not remineralization. Photooxidation, that increases bioavailability of fluvial dissolved organic matter (Wetzel 
et al., 1995), is also suggested as important mechanism for the removal of terrigenous dissolved organic matter (Benner \& Opsahl, 2001).

Mucilage aggregates appeared in the North Adriatic at late May and June. Electrochemical characteristics of the o-nitrophenol probe for the two samples of aggregates (Table 3) showed that general difference between aggregates sampled at the end of May and middle June was much higher surfactant activity of the later aggregates, 0.4 and $1.7 \mathrm{mg} / 1$ in equiv. of T-X-100, respectively. According to a small increase of prepeak height and a big shift of peak potential it is concluded that very hydrophobic lipid type substances mostly contributed to the surfactant activity of the aggregates. Although lipid fraction is not generally a relevant constituent of North Adriatic Sea mucilages, because it is never higher than $3 \% \mathrm{w} / \mathrm{w}$. (Mecozzi et al., 2001) lipids exerted dominant effects on the electrode surface. Estimated concentrations of lipid type substances are 0.2 and $1.7 \mathrm{mg} / \mathrm{l}$ in equiv. of oleic acid (see Figure 6b).

Changes of the o-nitrophenol probe in the presence of heterodispersed organic matter are illustrated in Figure 2, for the seawater sample from Station 101, surface layer from March. Comparing curves 3 and 4, that were obtained under same accumulation regime, it is evident that an occasional hit of a particle to the electrode surface caused big changes of electrochemical characteristics of the probe (curve 4). Changes of the onitrophenol probe in the presence of heterodispersed OM (curve 4), in all recorded cases, correspond to those of model substance albumin (compare curves 4 and 5). According to this it is supposed that heterodispersed fraction was mainly composed of protein type substances. High contribution of heterodispersed substances was found in March, July, September and December for most of the investigated stations, and for Stations A 001 and A 013 presence of this material was found during almost whole year. It is supposed that heterodispersed proteinaceous substances appeared in the period of phytoplankton blooms. It may be concluded that March, July, September and December were periods of phytoplankton blooms during 2000 for almost whole region. Exceptions were stations A 001 and A 013 where continuous supply of nutrients promotes consecutive phytoplankton blooms. Riverine-induced eutrophication causes many negative consequences as excess phytoplankton growth and increased frequency of blooms (Harding, Jr. et al., 1999). 
Although low molecular weight organic compounds make up the majority of dissolved organic matter a significant amount is composed of macromolecules (Guo et al., 1995). Recent studies have shown that marine colloids are mostly composed of macromolecules and are mostly organic in nature (Guo \& Santschi, 1997). Marine colloids are characterized also by having high proportions of bounded low molecular weight lipids, free fatty acids, phospholipids and hydrocarbons in comparison with truly dissolved material (Liu et al., 1998). Guo \& Santschi (1997) found decrease of colloidal organic matter from river to the sea and from surface to deeper water, and concluded that colloids are reactive component and that colloidal organic matter is transported from nearshore to offshore, being produced in the upper water column and than consumed during its transport to the deeper water. As SAS have same spatial distribution (Gašparović \& Ćosović, 2001) and according to the fact that, except hydrophobic organic matter, also high molecular weight hydrophilic compounds have surface-active properties it may be concluded that marine organic colloids mostly contribute to surfactant activity of organic matter in the North Adriatic seawater.

\section{Conclusions}

A typical characteristic of the SAS seasonal distribution was sinusoidal change during a year with higher amplitude detected in the surface layer. For the stations A 001 and A 013 such trend was not observed in the surface layer. Increased concentration of SAS for these two stations is attributed to SAS inputs by riverine waters and to nutrients inputs that promote phytoplankton production and excretion. Concentrations of SAS in the winter period are every investigated year at the observed minimum. Surfactant activity value in equiv. of $0.04 \mathrm{mg} / 1 \mathrm{~T}-\mathrm{X}-100$ can be considered as background value for the SAS in the eastern and $0.05 \mathrm{mg} / \mathrm{T}-\mathrm{X}-100$ in the western North Adriatic Sea, for the used method of determination, or expressed in equiv. concentration of humic acid it would be 0.3 and $0.4 \mathrm{mg} / 1$, respectively. 
Humic and fulvic substances were found to have higher contribution to the surfactant activity in the bottom layer. Biogenic organic matter, which is of lower relative acidity, contribute more to SA of surface layer, especially in the period from June to September. Half-life time of the fresh surface-active organic matter may be accounted less than few months. Heterodispersed SAS, composed mainly from the proteinaceous substances, were found in March, July, September and December and are ascribed to phytoplankton produced organic matter during a bloom. As this material was not found in samples a month later it is concluded that those substances are removed from the water column relatively fast, in a period less than one month. Exceptions were stations A 001 and A 013 where proteinaceous heterodispersed substances were found during whole year 2000 indicating continuous supply of nutrients that promoted consecutive phytoplankton blooms.

SAS were mostly distributed in the dissolved fraction during 2000, while particulate SAS contributed to the total SA less than $10 \%$, except in April and October when contribution of particulate fraction to SA increased up to 55 and $20 \%$, respectively. This high SA of particulate fraction may be ascribed to stickiness of organic material produced during assumed diatoms blooms at March and September. Such situation may lead to mucilage occurrence.

\section{Acknowledgements}

Financial support provided from the Croatian Ministry of Science and Technology is gratefully acknowledged. The authors thank the scientific staff and the crew of the RV "Vila Velebita" for collecting the samples. The data on basic hydrography are obtained by courtesy of the Center for Marine Research in Rovinj, Ruđer Bošković Institute, Croatia. We thank Dr Robert Precali for making these data available to us. Seawater samples from Station A 001 and A 013 were collected in the framework of the research and monitoring project organized by Istituto Centrale per la Ricerca Applicate al Mare (ICRAM). 


\section{References}

Afcharian, A., Levi, Y., Kiene, L. \& Scribe, P. 1997 Fractionation of dissolved organic matter from surface waters using macroporous resins. Water Research 12, 29892996.

Azam F. \& Cho, B. C. 1987 Bacterial utilization of organic matter in the sea. In Ecology of Microbial Communities (Fletcher, M., Gray, C. R. G. \&, Jones, J. G., Eds.). Cambridge Univ. Press, Cambridge, pp. 261-281.

Baines, S.B. \& Pace, M. L. 1991 The production of dissolved organic matter by phytoplankton and its importance to bacteria: Patterns across marine and freshwater systems. Limnology and oceanography 36, 1078-1090.

Benner, R., Pakulski, J. D., McCarthy, M., Hedges, J. I. \& Hatcher, P. G. 1992 Bulk Chemical Characteristics of Dissolved Organic Matter in the Ocean. Science 255, 1561-1564.

Benner, R. \& Opsahl, S. 2001 Molecular indicators of the sources and transformation of dissolved organic matter in the Mississippi river plume. Organic Geochemistry 32, 597-611.

Ćosović, B., Vojvodić, V. \& Pleše, T. 1985 Electrochemical determination and characterization of surface active substances in freshwaters. Water Research 19, 175183.

Degobbis, D. 1990 A stoichiometric model of nutrient cycling in the North Adriatic Sea and its relation to regeneration processes. Marine Chemistry 29, 235-253.

Degobbis, D. \& Gilmartin, M. 1990 Nitrogen, phosphorus and biogenic silicon budgets for the North Adriatic Sea. Oceanologica Acta 13, 31-45.

Degobbis, D., Fonda-Umani, S., Franco, P., Malej, A., Precali, R. \& Smodlaka, N. 1995 Changes in the North Adriatic ecosystem and the hypertrophic appearance of gelatinous aggregates. Science of the Total Environment 165, 43-58.

Derieux, S., Fillaux, J. \& Saliot, A. 1998 Lipid class and fatty acid distributions in particulate and dissolved fractions in the north Adriatic sea. Organic Geochemistry 29, 1609-1621. 
Franco, P., Jeftić, Lj., Malanotte-Rizzoli, P., Michelato, A. \& Orlić, M. 1982 Descriptive model of the North Adriatic. Oceanologica Acta 5, 379-389.

Fukushima, T., Ishibashi, T. \& Imai, A. 2001 Chemical Characterization of Dissolved Organic Matter in Hiroshima Bay, Japan. Estuarine, Coastal and Shelf Science 53, $51-62$.

Gašparović, B. \& Ćosović, B. 1994 Electrochemical estimation of the dominant type of surface active substances in seawater samples using o-nitrophenol as a probe. Marine Chemistry 46, 179-188.

Gašparović, B. \& Ćosović, B. 1995 Electrochemical reduction of o-nitrophenol as a tool for the rough characterization of organic matter in seawater samples. Electroanalysis 7, 1136-1142.

Gašparović, B., Vojvodić, V. \& Ćosović, B. 1997 Characterization of organic matter in fractionated seawater samples using o-nitrophenol as an electrochemical probe, Analitica Chimica Acta 338, 179-190.

Gašparović, B., Ćosović, B. \& Vojvodić, V. 1998a Contribution of organic acids to the pool of surface active substances in model and marine samples using o-nitrophenol as an electrochemical probe, Organic Geochemistry 29, 1025-1032.

Gašparović, B., Vojvodić, V. \& Ćosović, B. 1998b Excretion of Organic Matter During an Experimental Phytoplankton Bloom Followed by Using o-Nitrophenol as an Electrochemical Probe. Croatica Chemica Acta 71, 271-284.

Gašparović, B. \& Ćosović. B. 2001 Distribution of surface active substances in the North Adriatic Sea. Marine Chemistry 75, 301-313.

Gilmartin, M. \& Revelante, N. 1983 The phytoplankton of the Adriatic Sea: standing crop and primary production. Thalassia Jugoslavica 19, 173-188.

Gilmartin, M., Degobbis, D., Revelante, N. \& Smodlaka, N., 1990 The mechanism controlling plant nutrient concentrations in the northern Adriatic Sea. Int. Rev. Gesamten Hydrobiol. 75, 425-445.

Guo, L., Santschi, P. H. \& Warnken, K. W. 1995 Dynamics of dissolved organic carbon (DOC) in oceanic environments. Limnology and Oceanography 40, 1392-1403.

Guo, L. \& Santschi, P. H. 1997 Composition and cycling of colloids in marine environments. Reviews of Geophysics 35, 17-40. 
Harding, Jr. L. W., Degobbis, D. \& Precali, R. 1999 Production and fate of phytoplankton: Annual Cycles and Interanual Variability. In Ecosystems at the landsea margin drainage basin to coastal sea (Malone T. C., Malej, A., Harding, L. W., Smodlaka, N. \&, Turner, R. E., eds.). Coastal and Estuarine Studies, American Geophysical Union, Washington, DC, pp. 131-172.

Hubberten, U., Lara, R. J. \& Kattner, G. 1994 Amino acid composition of seawater and dissolved humic substances in the Greenland Sea. Marine Chemistry 45, 121-128.

Hunter, K. A. \& Liss, P. S. 1982 Organic sea surface films In Marine Organic Chemistry (Duursma, E. K., Dawson, R., eds.) Elsevier, Amsterdam, pp. 259-298.

Lampert, W. 1978 Release of dissolved organic carbon by grazing phytoplankton. Limnology and Oceanography 23, 831-834.

Liss, P. S. Chemistry of the sea surface microlayer. In Chemical Oceanography, Vol. 2. (Riley, J. P. \& Skirow, G., eds.) New York, Academic Press, 1975, p. 193-243.

Li, X. Y. \& Logan, B. E. 1995 Size distributions and fractal properties of particles during a simulated phytoplankton bloom in a mesocosm. Deep-Sea Research 42, 125-138.

Liu, Q., Parrish, C. C. \& Helleur, R. 1998 Lipid class and carbohydrate concentrations in marine colloids. Marine Chemistry 60, 177-188.

Mannino, A. \& Harvey, H. R. 2000 Biochemical composition of particles and dissolved organic matter along an estuarine gradient: Sources and implications for DOM reactivity. Limnology and Oceanography 45, 775-788.

Mecozzi, M., Romanelli, G., Amici, M. \& Pietrantonio, E. 2001 Characterization of the lipid fraction in marine mucilage samples by ultrasound extraction and TCL-FID analysis. Envchem/0112003.

Moran, M. A. \& Zepp, R. G. 1997 Role of photoreactions in the formation of biologically labile compounds from dissolved organic matter. Limnology and Oceanography 42, 1307-1316.

Mozetič, P., Fonda Umani, S., Cataletto, B. \& Malej, A. 1998 Seasonal and inter-annual plankton variability in the Gulf of Trieste (North Adriatic). Journal of Marine Science 55, 711-722.

Myklestad, S. M. 1995 Release of extracellular products by phytoplankton with special emphasis on polysaccharide. Science of the Total Environment 165, 155-164. 
Parlanti, E., Wörz, K., Geoffroy, L. \& Lamotte, M. 2000 Dissolved organic matter fluorescence spectroscopy as a tool to estimate biological activity in a coastal zone submitted to anthropogenic inputs. Organic Geochemistry 31, 1765-1781.

Pettine, M., Patrolecco, L., Camusso, M. \& Crescenzio, S. 1998 Transport of carbon and nitrogen to the North Adriatic Sea by the Po River. Estuarine, Coastal and Shelf Science 46, 127-142.

Pettine, M., Capri, S., Manganelli, M., Patrolecco, L., Puddu, A. \& Zoppini, A. 2001 The Dynamics of DOM in the North Adriatic sea. Estuarine, Coastal and Shelf Science 52, 471-489.

Plavšić, M. \& Ćosović, B. 2000 Adsorption properties of different polysaccharides on mercury in sodium chloride solutions. Electroanalysis 12, 895-900.

Revelante, N. \& Gilmartin, M. $1976 a$ The effect of Po river discharge on phytoplankton dynamics in the North Adriatic sea. Marine Biology 34, 259-271.

Revelante, N. \& Gilmartin, M. $1976 b$ Temporal succession of phytoplankton in the North Adriatic. Netherland Journal of Sea Research 10, 377-396.

Romankevich, E. A. 1984 Geochemistry of Organic Matter in the Ocean, SpringerVerlag, Berlin, Heidelberg, pp 187-198.

Santschi, P. H., Guo, L., Baskaran, M., Trumbore, S., Southon, J., Bianchi, T.S., Honeyman, B. \& Cifuentes, L. 1995 Isotopic evidence for the contemporary origin of high-molecular weight organic matter in oceanic environment. Geochimica et Cosmochimica Acta 59, 625-631.

Stumm, W. 1992 Chemistry of the Solid-Water Interface, New York, Wiley, pp 87-155.

Terzić. S., Ahel, M., Cauwet, G. \& Malej, A. 1998 Group-specific phytoplankton biomass/dissolved carbohydrate relationships in the Gulf of Trieste (North Adriatic). Hydrobiologia 363, 191-205.

Thurman, E. M. 1985 Organic Geochemistry of Natural Waters. Martinu Nijhoff and Dr W. Junk Publishers, Dordrecht, pp. 273-361.

Ulrich, H-J., Stumm, W. \& Ćosović, B. 1988 Adsorption of Aliphatic Fatty Acids on Aquatic Interfaces. Comparison between Two Model Surfaces: The Mercury Electrode and $\delta-\mathrm{Al}_{2} \mathrm{O}_{3}$ Colloids. Environmental Science and Technology 22, 37-41. 
Vichi, M., Zavatarelli, M. \& Pinardi, N. 1998 Seasonal modulation of microbially mediated carbon fluxes in the North Adriatic Sea - a model study. Fisheries Oceanography 7, 182-190.

Vojvodić, V., Ćosović, B. \& Mirić, V. 1994 Fractionation of surface active substances on the XAD-8 resin. Part I. Mixtures of model substances. Analitica Chimica Acta. 295, 73-83.

Vojvodić, V. \& Ćosović, B. 1996 Fractionation of surface active substances on XAD-8 resin: Adriatic Sea samples and phytoplankton culture media. Marine Chemistry 54, 119-133.

Wetzel, R. G., Hatcher, P. G. \& Bianchi, T. S. 1995 Natural photolysis by ultraviolet irradiance of recalcitrant dissolved organic matter to simple substrates for rapid bacterial metabolism. Limnology and Oceanography 40, 1368-1380.

Williams, P. M. \& Druffel, R. M. 1987 Radiocarbon in dissolved organic matter in the central North Pacific Ocean. Nature 330, 246-248.

Zoppini, A., Pettine, M., Totti, C., Puddu, A., Artegiani, A. \& Pagnotta, R. 1995 Nutrients, Standing Crop and Primary Production in Western Coastal Waters of the Adriatic Sea. Estuarine, Coastal and Shelf Science 41, 493-513. 


\section{Figure captions}

FIGURE 1. Sampling grid in the North Adriatic Sea where samples were collected for the study of surface-active properties of organic matter.

FIGURE 2. Current vs potential curves of $o$-nitrophenol probe added to the seawater sample taken at Station 101, surface, from March, 2000 (curves 1-4) obtained for different accumulation times (1 - $0 \mathrm{~min}, 2-1 \mathrm{~min}, 3-3 \mathrm{~min}$ and $4-3 \mathrm{~min}$ ). Current vs potential curves of $o$-nitrophenol probe in the presence of $0.8 \mathrm{mg} / 1$ albumin, $3 \mathrm{~min}$ accumulation time (curve 5). Curves 1-5 represent main $o$-nitrophenol peak, and curves $1 \mathrm{~A}$ - 5A represent prepeak.

FIGURE 3. Variations of surfactant activity (1-0-surface and 2-•-bottom layer) (a, c) and temperature (3- $\Delta$-surface and 4- $\boldsymbol{\Delta}$-bottom layer) and salinity (5- $\square$-surface and 6- $\mathbf{-}$ bottom layer) (b, d), for the station 107, in a period from 1998 to 2000; and station A 001 in the year 2000 .

FIGURE 4. Variations of surfactant activity (1-o-surface and 2-•-bottom layer) (a, c, e) and temperature (3- $\Delta$-surface and 4- $\mathbf{\Delta}$-bottom layer) and salinity (5- $\square$-surface and 6- $\mathbf{-}$ bottom layer) (b, d, f) obtained for the stations A 013 and 108 left part and stations A 001 to RV 001 right hand side, measured in February (a and b), August (c and d) and December (e and f) in 2000.

FIGURE 5. Percentage of contribution of surfactant activity of particulate fraction $\left(\mathrm{SA}_{\mathrm{p}}\right)$ to total SA during year 2000.

FIGURE 6. Scatter plot of dependence of the relative acidity on the surfactant activity of humic acid (1), fulvic acid (2), albumin (3), acidic polysaccharide xanthan (4), neutral polysaccharide dextran T-500 (5), and linoleic acid (6) (a). Dependance of the surfactant activity on increased concentration for the same model substances. Accumulation time was $3 \min (b)$. 
Table 1 . Averaged relative acidity values $(1 / \mathrm{mg})$ evaluated on the monthly bases for all stations, for bottom and surface layers

\begin{tabular}{|l|c|c|}
\hline $\begin{array}{l}\text { Month } \\
2000\end{array}$ & bottom & surface \\
\hline Jan & 18.9 & 16.0 \\
Feb & 17.3 & 15.5 \\
March & 21.6 & 15.4 \\
Apr & 23.2 & 16.0 \\
May & - & - \\
June & 18.0 & 11.7 \\
July & 20.7 & 14.0 \\
Aug & 19.3 & 10.8 \\
Sept & 17.7 & 15.3 \\
Oct & 19.2 & 15.7 \\
Nov & - & - \\
Dec & 19.9 & 15.3 \\
\hline
\end{tabular}


Table 2. Averaged relative acidity values (2000) evaluated for investigated stations during one year for bottom and surface layers

\begin{tabular}{|l|l|l|}
\hline $\begin{array}{l}\text { Station } \\
2000\end{array}$ & bottom & surface \\
\hline RV 001 & 21.0 & 15.4 \\
107 & 19.0 & 14.3 \\
105 & 18.6 & 14.5 \\
103 & 18.6 & 14.0 \\
101 & 20.8 & 14.1 \\
A 001 & 20.1 & 15.3 \\
108 & 17.9 & 14.1 \\
A 013 & 17.9 & 14.7 \\
\hline
\end{tabular}


Table 3. North Adriatic mucillage samples

\begin{tabular}{|c|c|c|c|c|}
\hline \multirow[t]{2}{*}{ Sample } & $\Delta \mathrm{E} / \mathrm{mV}^{1}$ & \multirow{2}{*}{$\begin{array}{l}\mathrm{SA}^{2}(\mathrm{mg} / \mathrm{l} \\
\mathrm{T}-\mathrm{X}-100)\end{array}$} & $\mathrm{I}_{\mathrm{A}} / \mathrm{I}_{\mathrm{A} 0^{3}}$ & \multirow[t]{2}{*}{ Relative acidity $^{4}$} \\
\hline & $3 \mathrm{~min}$ & & $3 \mathrm{~min}$ & \\
\hline \multicolumn{5}{|l|}{ Mucilage } \\
\hline $31-05-2000(1 / 5)^{5}$ & 30 & 0.4 & 1.26 & $3.3^{7}$ \\
\hline $16-06-2000(1 / 10)^{6}$ & 121 & 1.7 & 0.85 & $<3^{7}$ \\
\hline
\end{tabular}

${ }^{1}$ Shift of peak potential for 1 and 3 min of accumulation.

${ }^{2}$ Surfactant activity expressed in equiv. concentration of nonionic tenside Triton-X-100, calculated for the original sample.

${ }^{3}$ Normalized prepeak height for 1 and 3 min of accumulation.

${ }^{4}\left(\mathrm{I}_{\mathrm{a}} / \mathrm{I}_{\mathrm{a} 0}\right)-1 / \mathrm{SA}$

${ }^{5}$ Dilution of sample 5 times.

${ }^{6}$ Dilution of sample 10 times.

${ }^{7}$ Decreasing part of the relative acidity curve (see Fig. 6a). 
Figure 1.

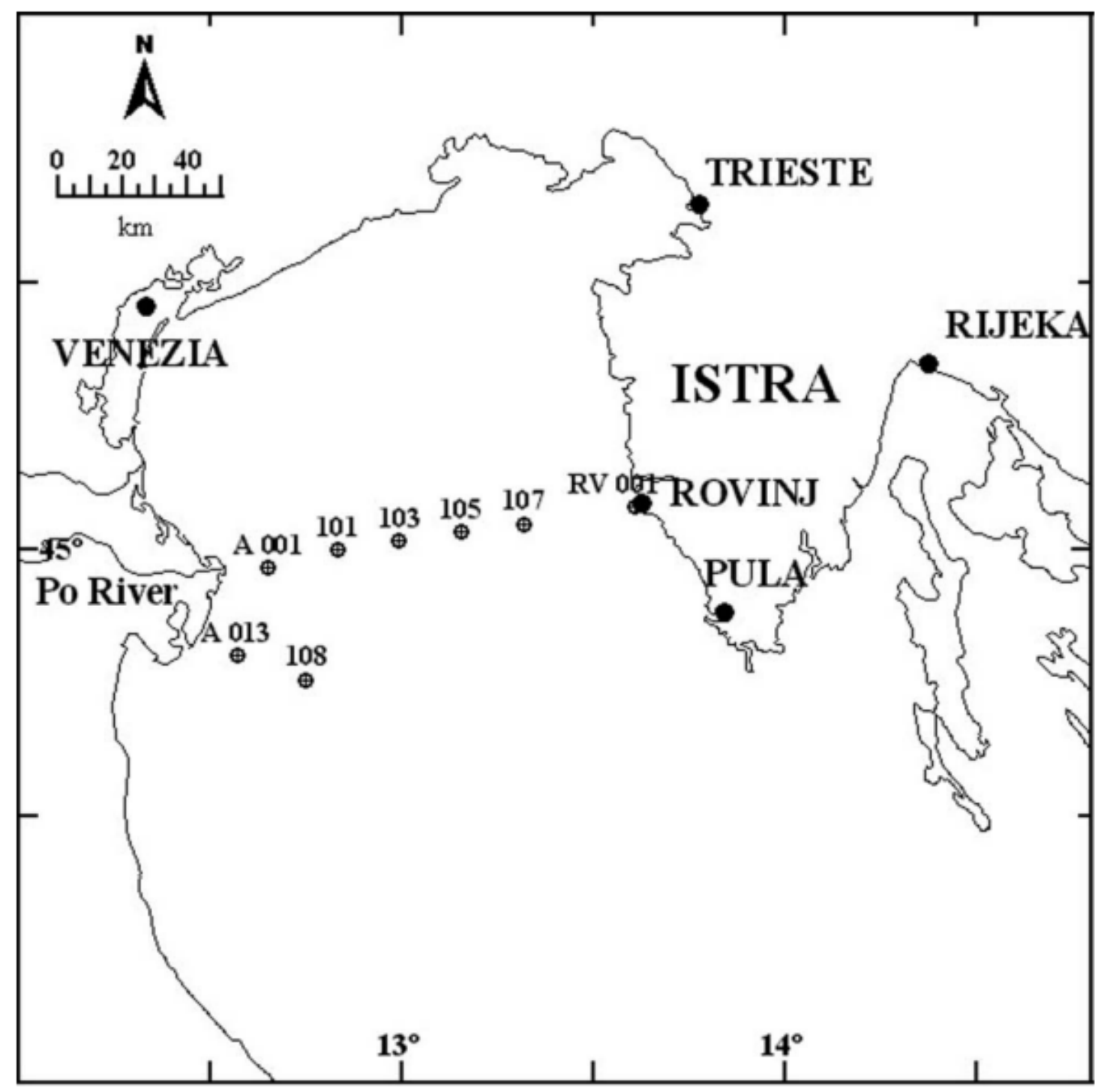


Figure 2.

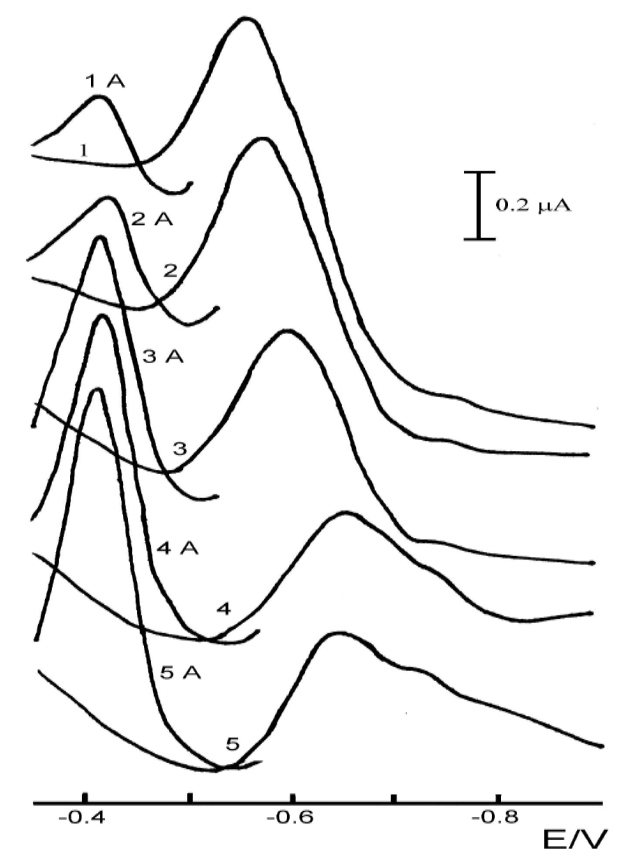


Figure 3a.

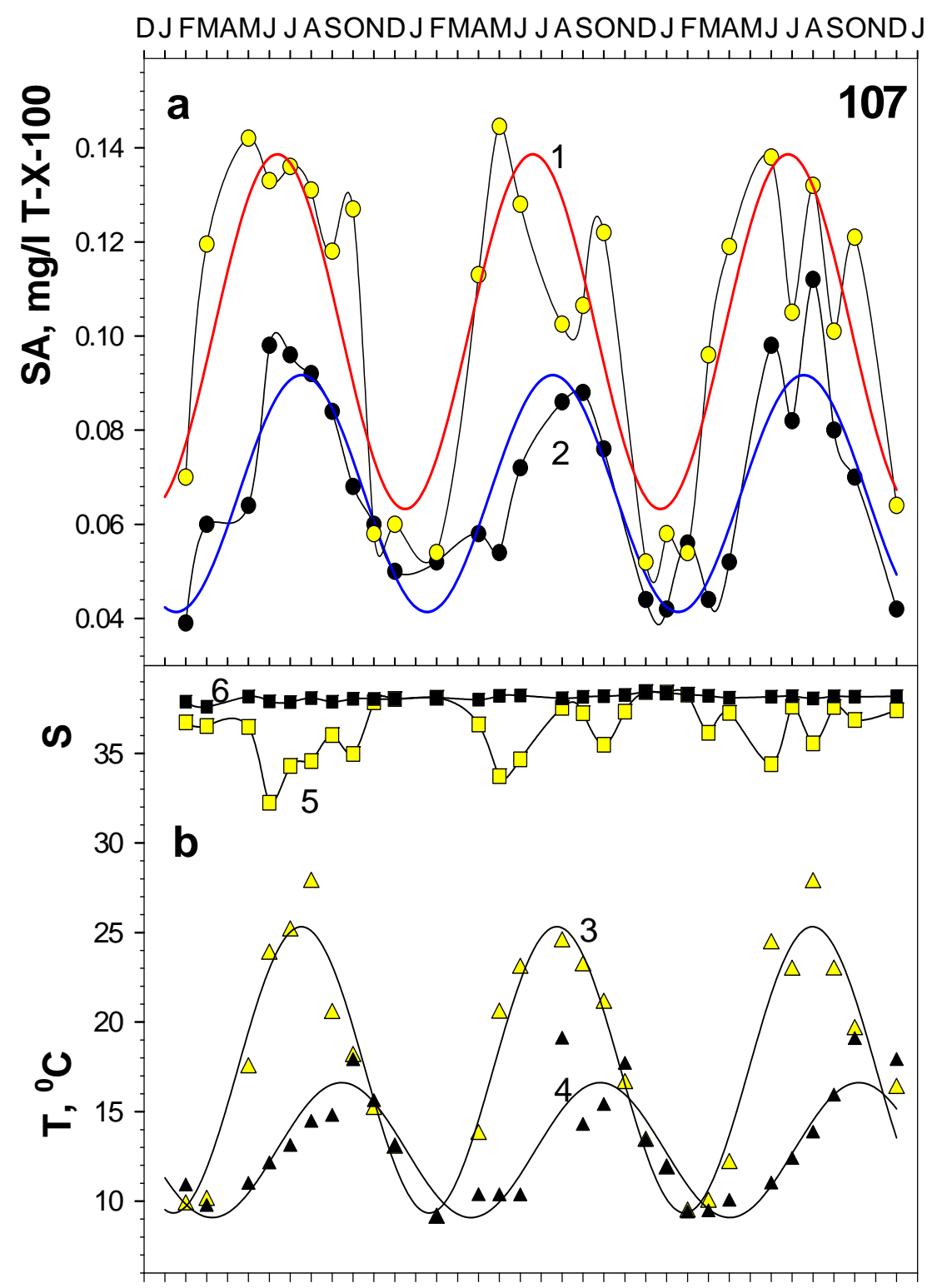

DJ FMAMJ J ASOND J FMAMJ J ASOND J FMAMJ J ASOND J 1998 1999 2000 
Figure $3 b$.

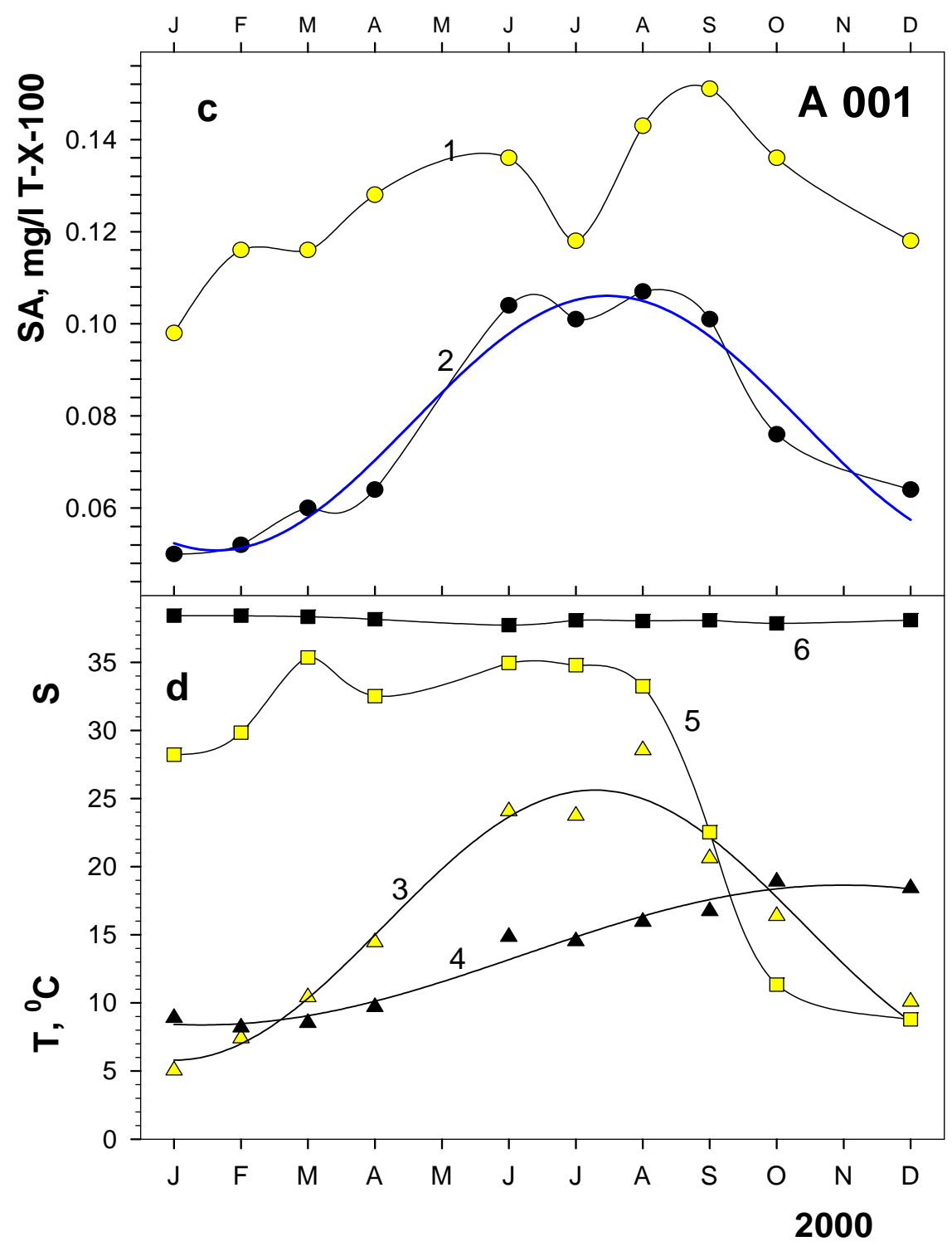


Figure 4.
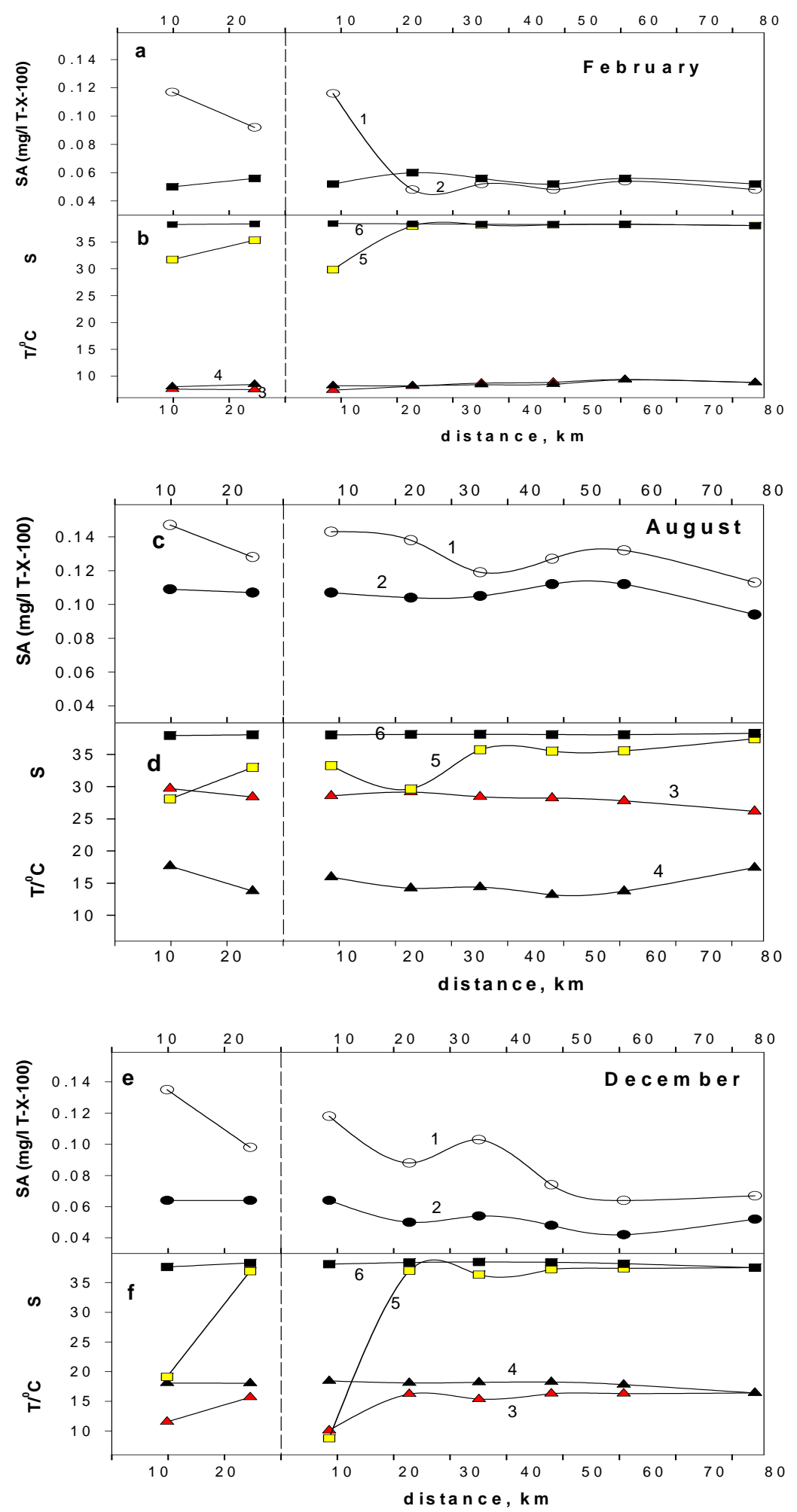
Figure 5.

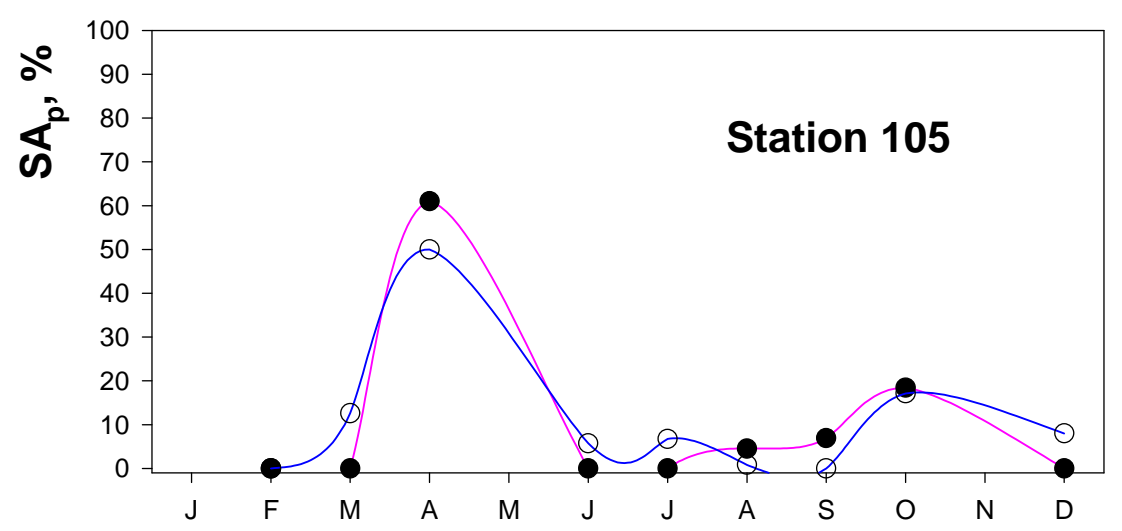

2000 
Figure 6.
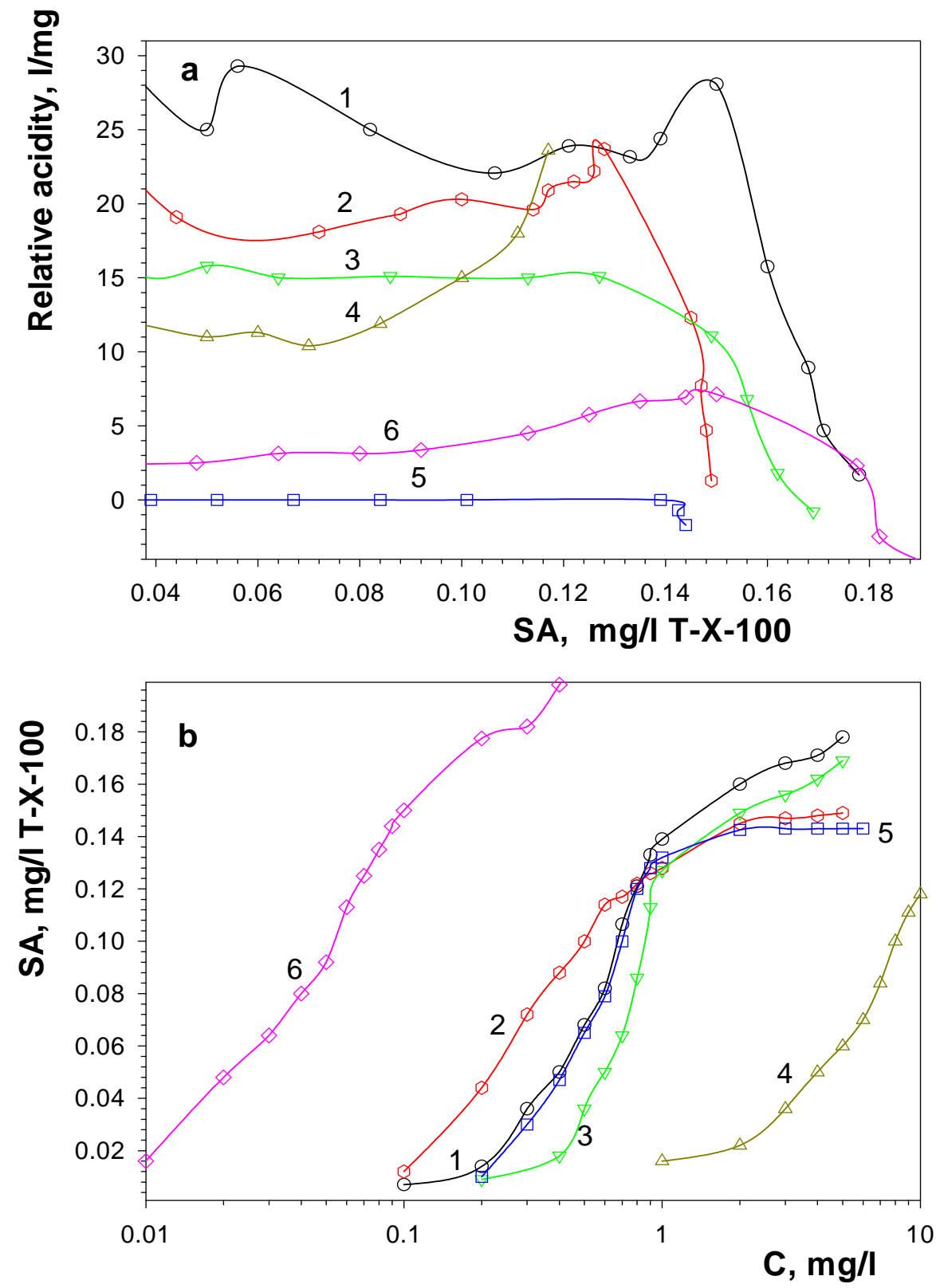